\title{
CORRECTION
}

\section{Correction to: CAFT: a deep learning-based comprehensive abdominal fat analysis tool for large cohort studies}

\author{
K. N. Bhanu Prakash ${ }^{1}$ (D) Channarayapatna Srinivas Arvind ${ }^{1} \cdot$ Ling Yun Yeow ${ }^{1} \cdot$ Wen Xiang Chen $^{2} \cdot$ Wee Shiong Lim $^{3}$. \\ Cher Heng Tan ${ }^{2}$
}

Published online: 4 September 2021

(c) European Society for Magnetic Resonance in Medicine and Biology (ESMRMB) 2021

\section{Correction to: \\ Magnetic Resonance Materials in Physics, Biology and Medicine \\ https://doi.org/10.1007/s10334-021-00946-9}

The original version of this article unfortunately contained a mistake. Author name K. N. Bhanu Prakash was incorrectly written as Prakash K. N. Bhanu.
Publisher's Note Springer Nature remains neutral with regard to jurisdictional claims in published maps and institutional affiliations.
The original article can be found online at https://doi.org/10.1007/ s10334-021-00946-9.

K. N. Bhanu Prakash

bhanu@ibb.a-star.edu.sg

Channarayapatna Srinivas Arvind arvind_channarayapatna_srinivasa@ibb.a-star.edu.sg

Ling Yun Yeow yeow_ling_yun@ibb.a-star.edu.sg

Wen Xiang Chen

chen_wen_xiang@ttsh.com.sg

Wee Shiong Lim

wee_shiong_lim@ttsh.com.sg
Cher Heng Tan

cher_heng_tan@ttsh.com.sg

1 Signal and Image Processing Group, Institute of Bioengineering and Bioimaging, 02-02, Helios, 11, Biopolis Way, Singapore 138667, Singapore

2 Department of Diagnostic Radiology, Tan Tock Seng Hospital, 11 Jln Tan Tock Seng, Singapore 308433, Singapore

3 Department of Geriatric Medicine, Tan Tock Seng Hospital, 11 Jln Tan Tock Seng, Singapore 308433, Singapore 